\title{
Bacterial foraging optimization based adaptive neuro fuzzy inference system
}

\author{
C. Arul Murugan 1 , G. Sureshkumar ${ }^{2}$, Nithiyananthan Kannan ${ }^{3}$, Sunil Thomas $^{4}$ \\ ${ }^{1}$ Department of Electronics and Telecommunication Engg, Karpagam College of Engineering, India \\ ${ }^{2}$ Department of Electronics and Instrumentation Engineering, Karpagam College of Engineering, India \\ ${ }^{3}$ Department of Electrical Engineering, Faculty of Engineering, Rabigh, King Abdulaziz University, Saudi Arabia \\ ${ }^{4}$ Department of Electrical and Electronics Engineering, Birla Institute of Technology and Science, United Arab Emirates
}

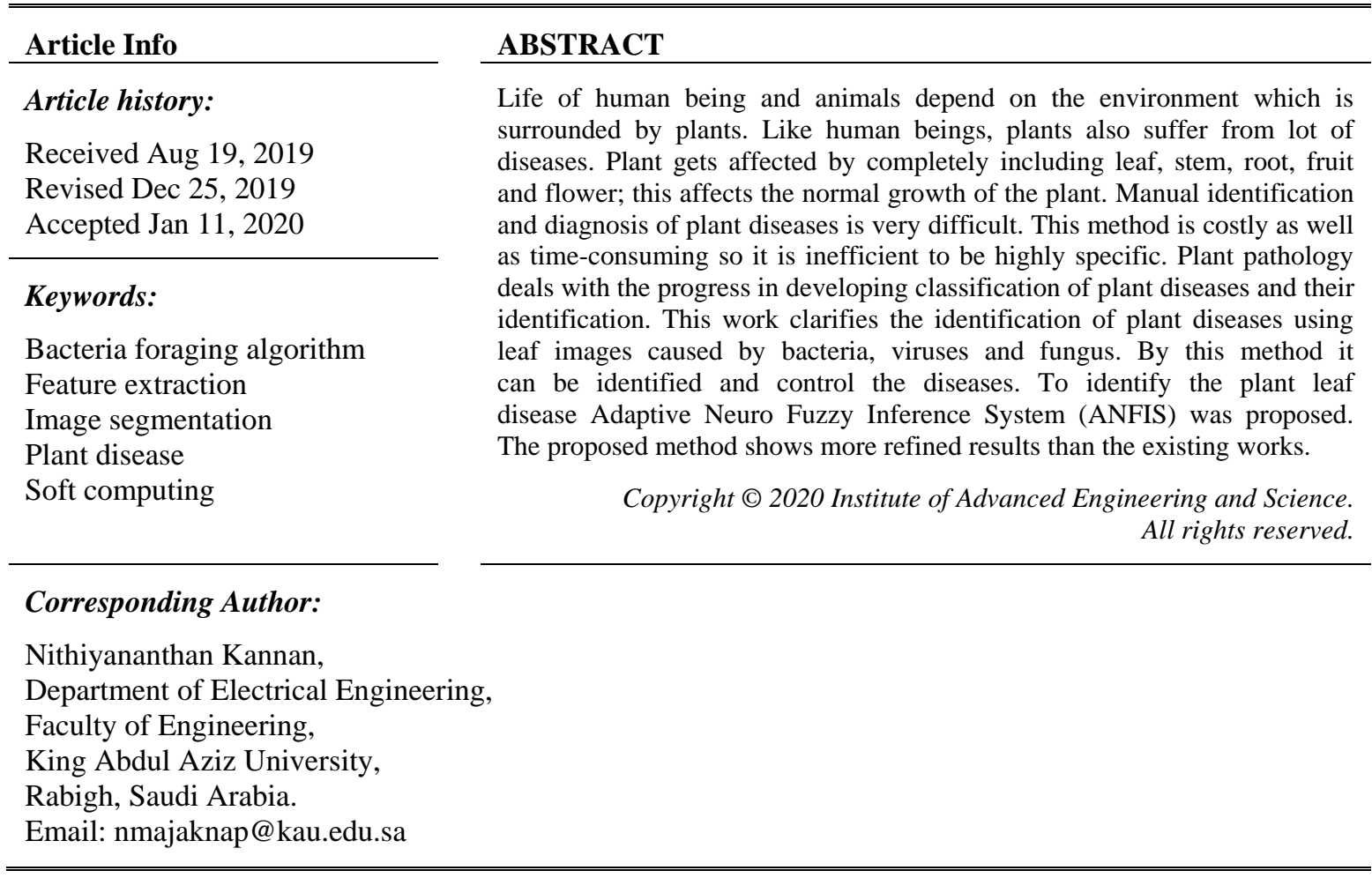

\section{INTRODUCTION}

Indian Economy is necessitous in the role of agriculture. India is an agriculture based country, where more than $50 \%$ of population depends on agriculture. Like human being plants also get affected from diseases, to prevent this farmers must use suitable pesticides for crops. Both the quantity and quality of crops get affected due to diseases. Visual observation of a plant is done by plant pathology. Computer devices act as a consequential role in numerous applications such as defense, agriculture, medical and engineering. Huge number of research has been reported [1-35]. In early days, the expertise person in the field manually analyses and diagnosis the plant disease which are too difficult to be monitored and also it required more time. Plant serve as a backbone in all aspects of life, plants also suffer from diseases which affects the normal growth of the plant.

In this article, it has been presented an automatic soft computing approach named ANFIS to identify and classify diseases of plant leaves. Image segmentation is done to split the leaf images into smaller parts for clear identification of affected parts of leaf. Image segmentation is done with the texture, color and shape of an image. Segmentation is the preprocessing technique which comprises of soft computing and traditional method. Soft computing is an automatic method which is used for complex task (i.e. image segmentation) without human knowledge. 


\section{RELATED WORK}

In this technique [36] plant diseases symptoms was identified and it was tested using algorithm to achieve better accuracy. Conduct an investigation [37] in classification methods to get rid of errors and also discussed the models to extract information in infected leaf. In [38] proposed a methodology in four different phases to support accurate differentiation of leaf diseases and classify the detection. Comparison was made for segmentations using automated tool and leaf symptoms were identified [39]. An inventive technique elicited from OCM [40] was introduced to analyze the leaf mechanism and the leaf spots provide stability in the framework of hybrid algorithms. In this work [41] a new approach was considered to emulate the results and the portions of leaf are combined to address the image analysis. It is widely used to adapt the segmentation in a general measure of bias. The images were automatically classified [42] in a training set to facilitate accuracy in deep learning models. Approaches involved have the potential to identify the species of perspective models. Evaluation was made for running time and accuracy also guidelines were given to overcome the problems in future research works [43]. In [44], bacterial spot was assessed and also evaluated the severity of diseases which are inaccurate causing lesions on leaves. Using some modifications visual methods quantify the potential risk of infection. The diseased areas of each leaf are collected to facilitate digital scanning. The author proposed an algorithm [45] to identify the results of maize disease in the detection of plant leaf. A data point in same class is a prime technique to enhance colour analysis in favor of feature extraction. In this research work $[46,47]$ depicts a prototype called eAGROBOT to detect the crop disease.

\section{RESEARCH METHOD}

In this paper the plant leaf disease is analyzed and predicted by using Adaptive Neuro Fuzzy Inference System. Basically human beings calculate the characteristics of a particular thing by comparing the predetermined value obtained by other authors. Similarly system analyses the same predetermined values to obtain the expected result. Feature extraction is related to dimensionality reduction. With the help of ANFIS, the proposed algorithm achieves higher accuracy.

\section{PLANT DISEASE}

Similar to human beings and animals reveal symptoms of suffer from diseases. The entire plant gets affected by the diseases including flower, root, leaf, stem and fruit. Most of the time it is difficult to identify the plant under various factors which may cause leaves drop, flower and fruit. Well-defined treatment and identification of plant diseases is required for growth of certain factors and appropriate diagnosis. The aspects for diagnosis of diseases depends on

- Glancing for symptoms or signs: the appearance of some unwanted spots, curls and dead areas are visible to the naked eyes.

- Awareness of the normal characteristics of host plant: it is easier for one to diagnosis the plant disease if one should know the inheritances and assets of the host plants.

- The occurrences of symptoms: it depends upon two factors (i) the Disorder, (ii) Diseases some environmental problems lead to disorders, it happens suddenly like within a day or week and does spread over the parts of the plants.

- Detecting the diseases of the host plant in nature pattern is of two types uniform and non-uniform. Non-living factors are the cause for uniform pattern whereas non-uniform pattern is caused by some disease or insect. The disease classification and its effect, symptoms of fungal plant are explained in Table 1.

Table 1. Fungal plant disease classification

\begin{tabular}{|c|c|c|c|c|}
\hline Leaf Image & Diseases name & Effect & $\begin{array}{c}\text { Suitable Climatic } \\
\text { Condition }\end{array}$ & Symptoms/Cause \\
\hline & Common rust & $\begin{array}{l}\text { Roses, hollyhocks, } \\
\text { snapdragons get } \\
\text { affected }\end{array}$ & Low temperature & $\begin{array}{l}\text { Appears primarily on the } \\
\text { surface of lower leaf, reddish } \\
\text { orange spore mass }\end{array}$ \\
\hline
\end{tabular}


Table 1. Fungal plant disease classification (Continue)

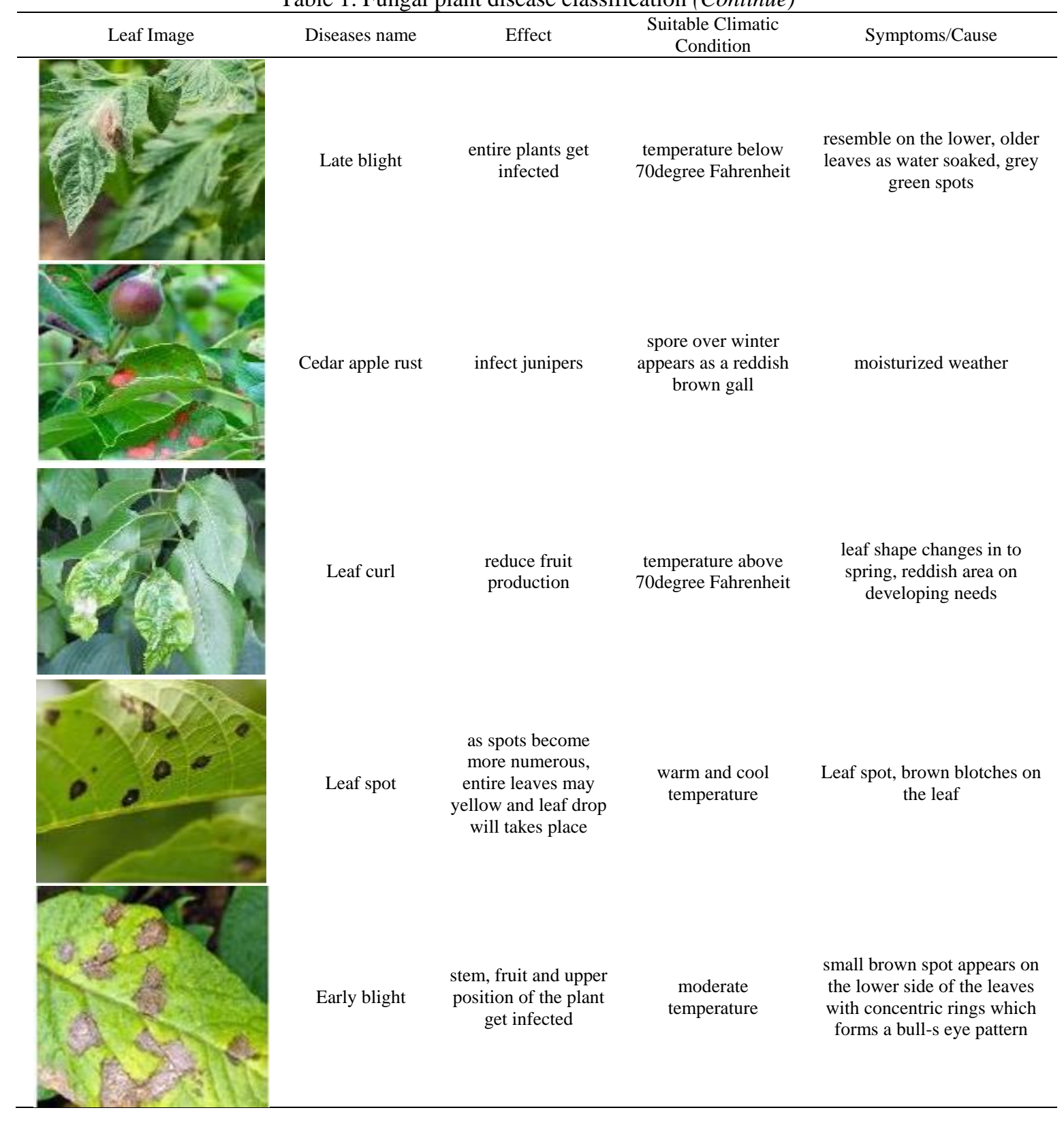

\section{PROPOSED WORK}

In the proposed work, it has been spirited on identification and classification of plant diseases using a few computational and intelligence advance. The perfection research area is emerging for the development of an automated system for identifying and classifying the adulterated plants with different diseases. To prevent the qualitative and quantitative loss of agricultural yields identification of diseases is the only way. The limitation of human vision can be overcome by the accurate and timely detection of diseases with the help of image processing techniques. The leaf image is pre-processed initially. Using adaptive k-means diseases part is segmented. Texture and statistical technique are also included to obtain high pass version of feature extraction.

\subsection{Image acquisition}

The acquired image is enhanced by using UN sharp filter, by filtering a UN sharp version in dark image from the original image. It filters the edges. When compared with negative of the Laplacian filter the parameter alpha is used for unsharp filter and the alpha value is selected as 0.2 , by the 'fspecial'. K-means method is used for image segmentation and flowchart for the proposed approach is shown below in Figure 1. 


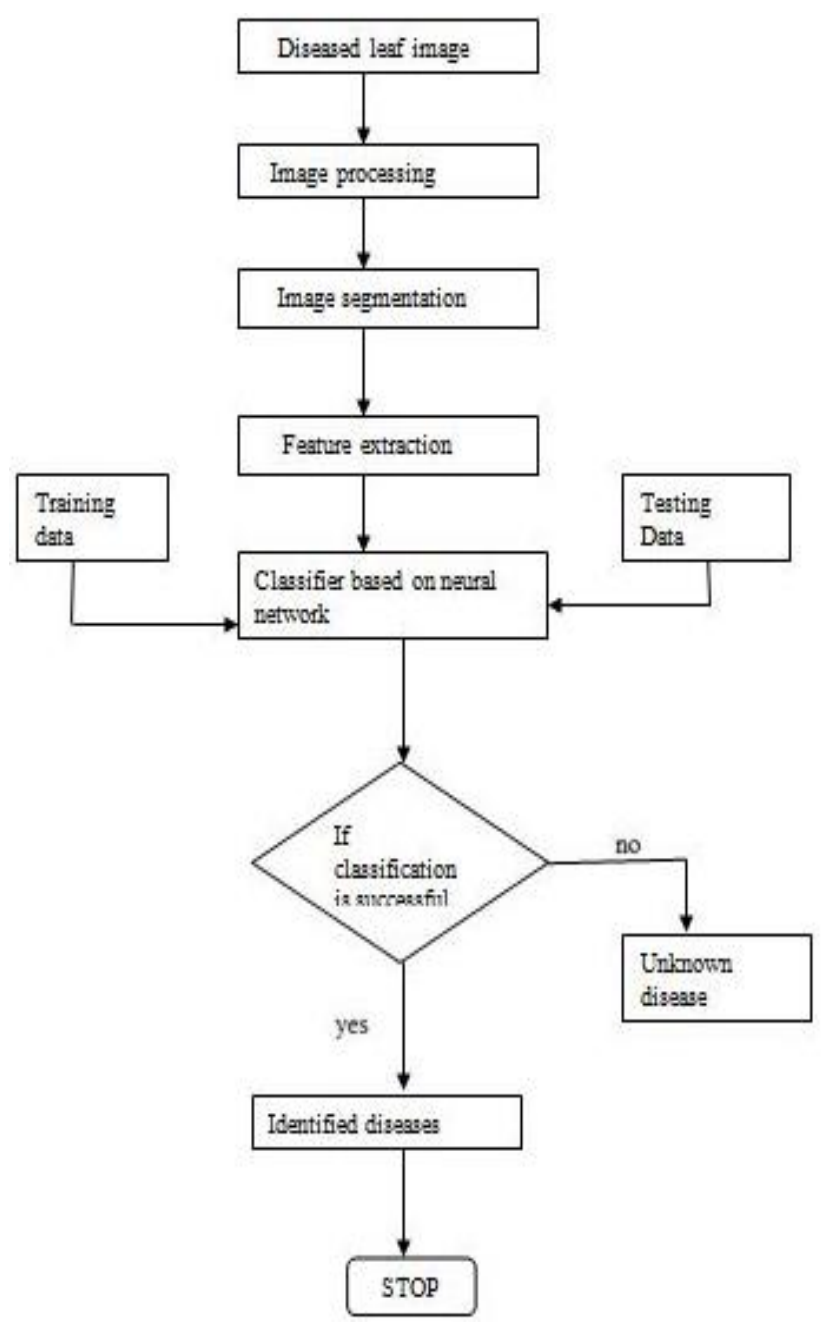

Figure 1. Flowchart for proposed approach

\section{RESULTS AND ANALYSIS}

The proposed work was implemented on MATLAB 2014a. For justifying the success of this work we have taken two set of images. First we have taken 6 set of images as an input images which are affected by diseases caused by fungi and second step we have finally two hundred and seventy images. The affected region of the leaf part is identified by segmentation of pixels. The proposed work is done successfully with the accurate value that is the diseases are classified perfectly. For classification the parameters are required are specificity and Sensitivity. The affected area of leaf part are observed and presented in Table 2 with their classifications.

Table 2. Results for ANFIS, (a) Original image, (b) Segmented grayscale image, (c) Mask image, (d) Results for segmented leaf disease

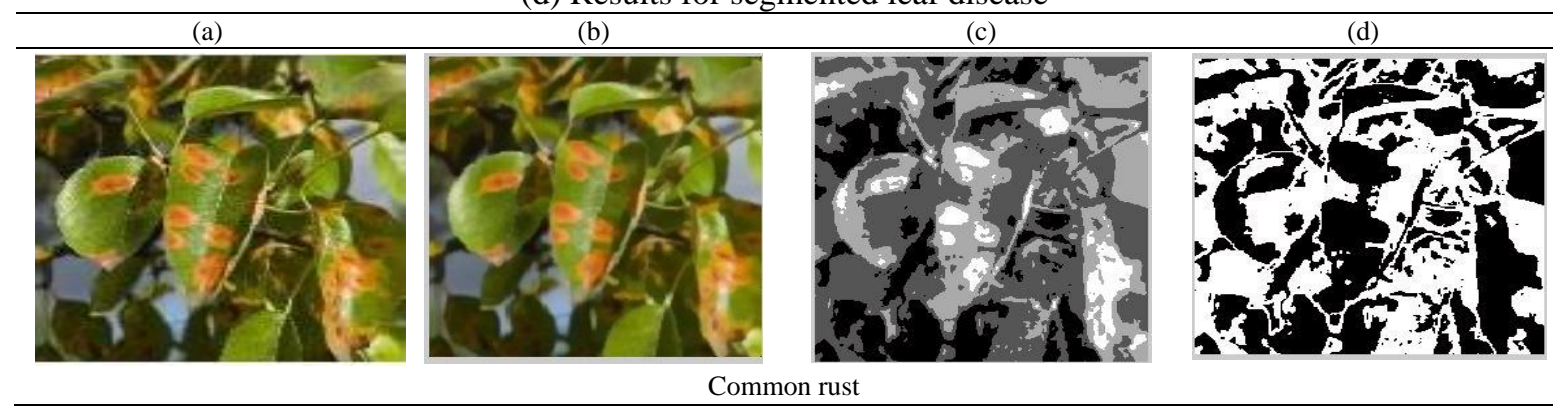


Table 2. Results for ANFIS, (a) Original image, (b) Segmented grayscale image, (c) Mask image, (d) Results for segmented leaf disease (Continue)
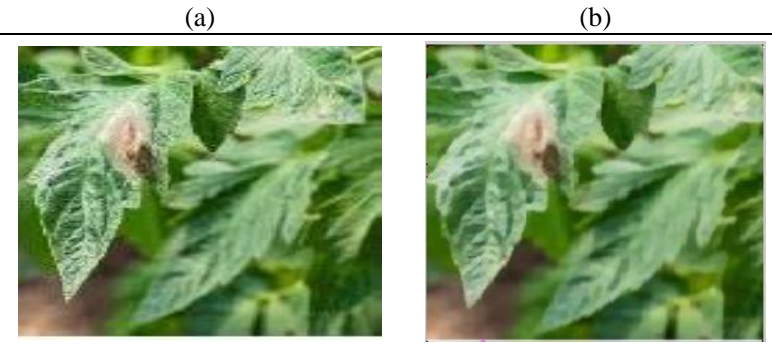

(c)

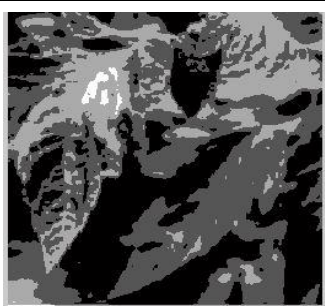

Late blight
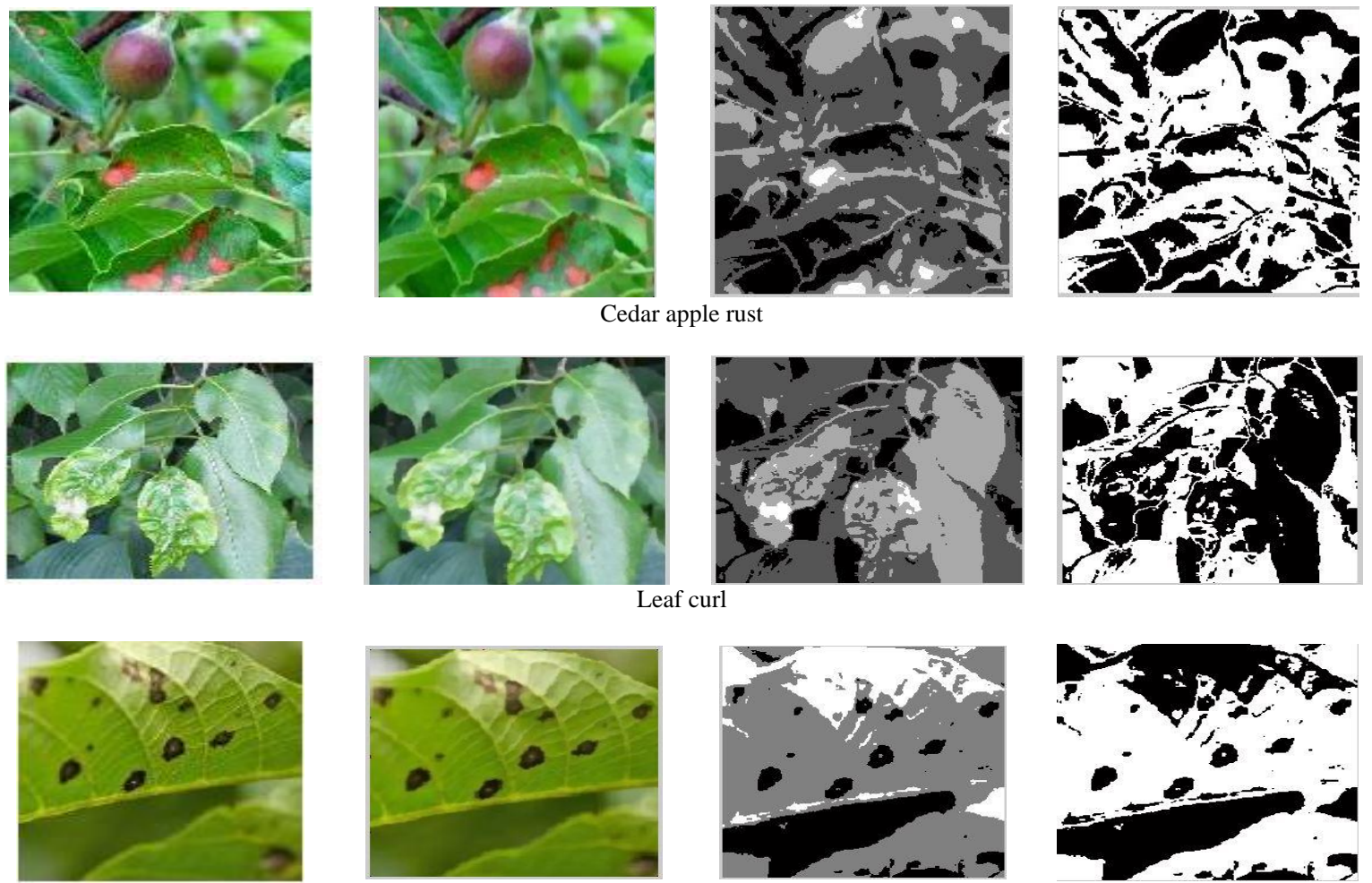

Leaf spot
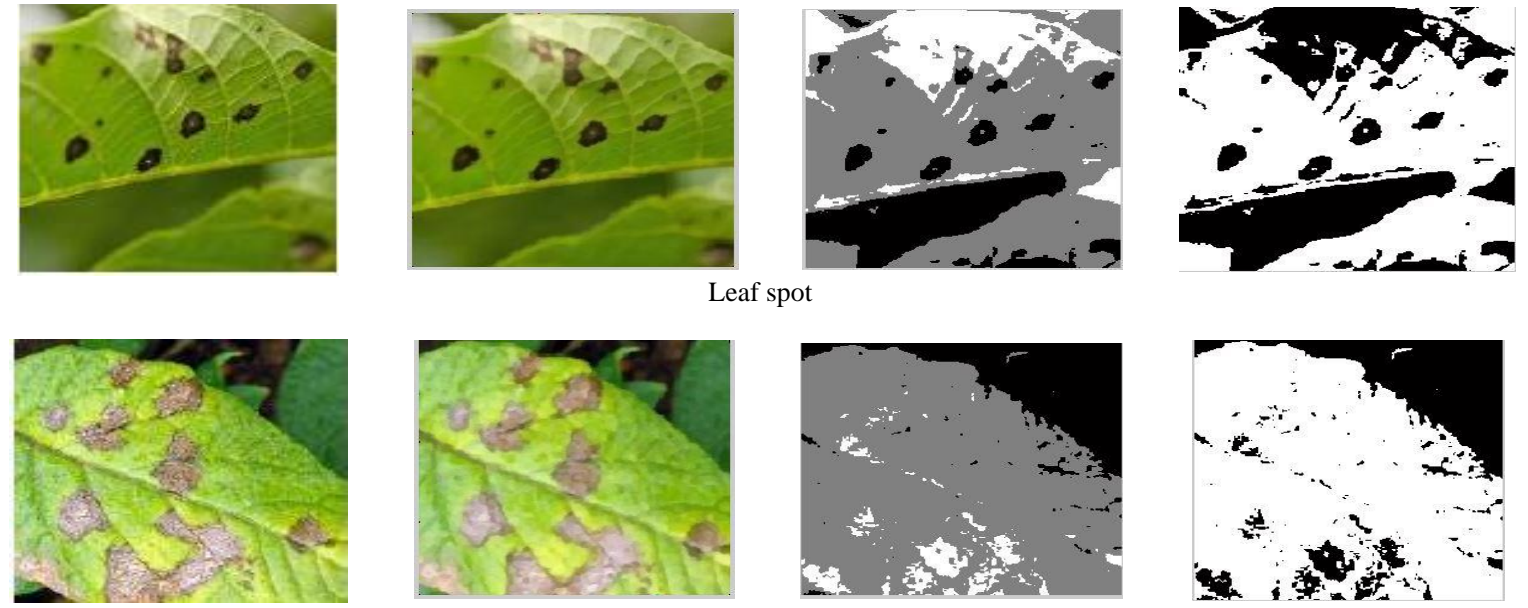

Early blight

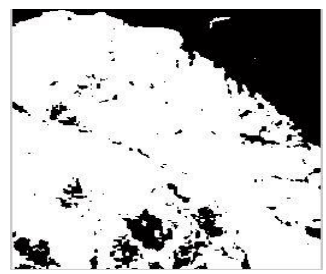

Plant leaf diseases depends on its own feature refers to symptoms. Features like shape, color and size can be determined by feature extraction. To search seed points and to group them region growing method is used in feature extraction. For well-defined examination defined the input image is converted into segmented gray scale image. Specificity and Sensitivity validation parameters used in the proposed work. Adaptive K-means is used for evaluating the segmentation process. Table 3 shows the report of specificity for the proposed algorithm along with the comparison of existing algorithms. Table 4 shows the report of sensitivity for the proposed algorithm along with the comparison of existing algorithms. The pictorial representation of detected leaf diseases for proposed and existing algorithms with specificity results is shown in Figure 2. The pictorial representation of detected leaf diseases for proposed and existing algorithms with sensitivity results is shown in Figure 3. 
Table 3. Comparison of specificity results for detection of leaf diseases

\begin{tabular}{ccccc}
\hline Disease & K-means & Genetic algorithm & BRBFNN & ANFIS \\
\hline Common rust & 0.7817 & 0.8096 & 0.8213 & 1.0000 \\
Late blight & 0.8014 & 0.8205 & 0.8326 & 0.8571 \\
Cedar apple rust & 0.7801 & 0.7854 & 0.8196 & 1.0000 \\
Leaf curl & 0.7517 & 0.7889 & 0.8879 & 0.8571 \\
Leaf spot & 0.8124 & 0.8318 & 0.8836 & 1.0000 \\
Early blight & 0.8211 & 0.8374 & 0.8897 & 0.8571 \\
Average specificity & 0.7914 & 0.8139 & 0.8558 & 0.9285 \\
\hline
\end{tabular}

Table 4. Comparison of sensitivity results for detection of leaf disease

\begin{tabular}{ccccc}
\hline Disease & k-means & Genetic algorithm & BRBFNN & ANFIS \\
\hline Common rust & 0.8078 & 0.8117 & 0.8311 & 1.0000 \\
Late blight & 0.8189 & 0.8339 & 0.8497 & 1.0000 \\
Cedar apple rust & 0.7809 & 0.7996 & 0.8407 & 0.8571 \\
Leaf curl & 0.7729 & 0.8279 & 0.8938 & 1.0000 \\
Leaf spot & 0.8111 & 0.8315 & 0.9078 & 1.0000 \\
Early blight & 0.8201 & 0.8471 & 0.8999 & 1.0000 \\
Average sensitivity & 0.8020 & 0.8244 & 0.8705 & 1.0000 \\
\hline
\end{tabular}

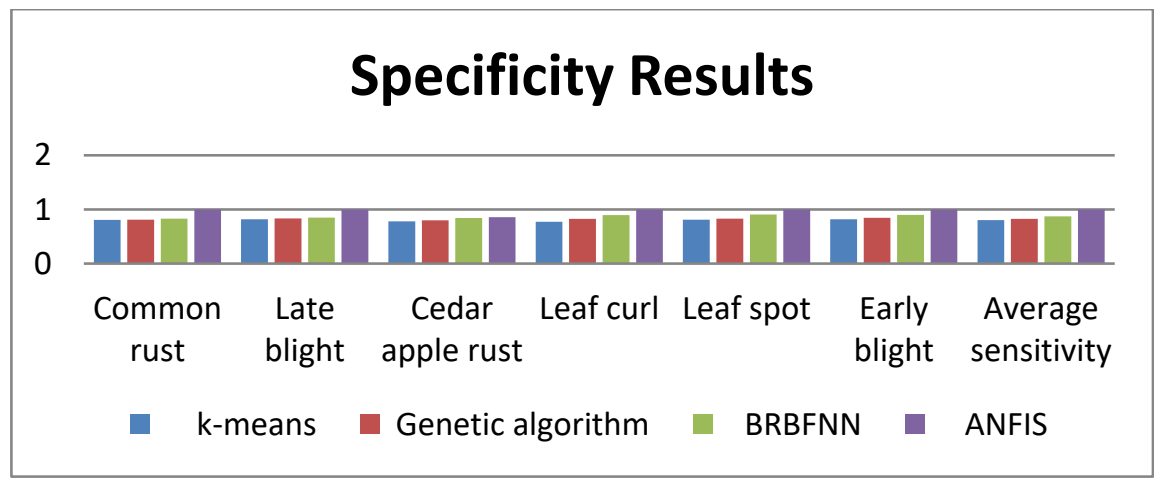

Figure 2. Inference for specificity interpretations

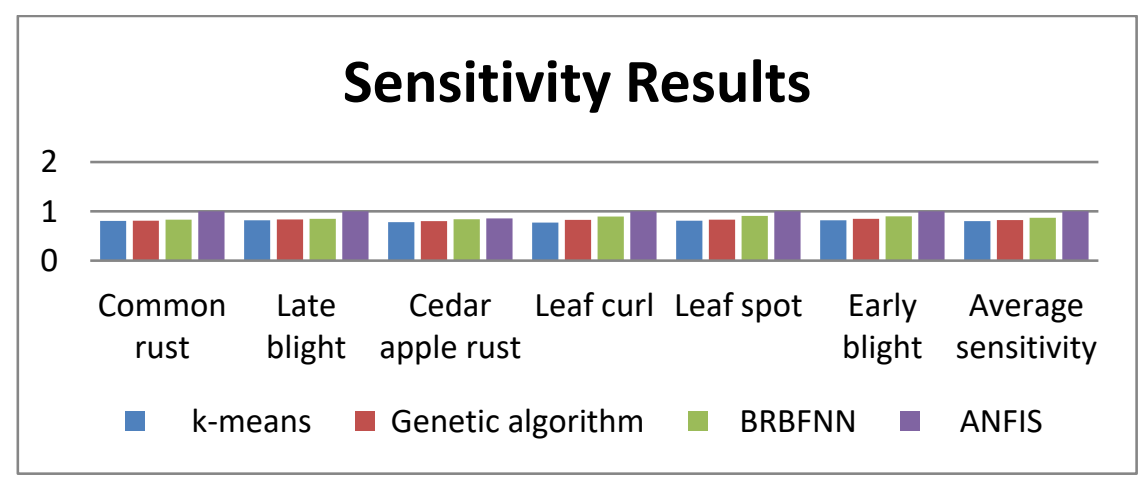

Figure 3. Inference for sensitivity interpretations

\section{CONCLUSION}

If human beings get affected by diseases, it has been cured by itself consulting a doctor, but plants should be observed by human beings to prevent the diseases. But human observation for a prolonged time is impossible and it is difficult. To overcome this, an automatic approach was designed which helps to monitor the plant leaves and identify the leaf disease. This automatic approach clearly identifies the disease and disease can be cured at earlier stage. For identifying the plant leaf diseases ANFIS has been used. While comparing to the existing algorithm results, the proposed algorithm shows 90 percent results. Proposed work shows higher accuracy and effectiveness. Proposed work has been successfully done on fungal diseases, in future it can be expected to work on bacteria and viruses. 


\section{REFERENCES}

[1] Sunil Thomas, K.Nithiyananthan, "A Novel method to implement MPPT Algorithms for PV panels on a MATLAB/SIMULINK environment," Journal of Advanced Research in Dynamical and Control Systems, vol. 10, no 4, pp.31-40, 2018.

[2] Gowrishankar. K., Sunil Thomas, K. Nithiyananthan, "Wireless Integrated-Sensor Network based Subsea Tunnel Monitoring System," Journal of Advanced Research in Dynamical and Control Systems, vol. 10, No 12, pp.647-658, 2018.

[3] Gowrishankar.K. K.Nithiyananthan., M.Priyanka, Sunil Thomas, GSM based dual power enhanced LED display notice board with motion detector," International Journal of Engineering and Technology, vol. 7, pp. 559-566, 2018.

[4] Syahrel Emran Bin Siraj, Tan Yong Sing, Raman Raguraman, Pratap Nair Marimuthu, K. Nithiyananthan, "Application of Cluster Analysis and Association Analysis Model Based Power System Fault Identification," European Journal of Scientific Research, vol. 138, pp. 16-28, 2016.

[5] K. Nithiyananthan, Pratap Nair, Raman Raguraman, Tan Yong Sing, Syahrel Emran Bin Siraj, "Enhanced R package-based cluster analysis fault identification models for three phase power system network," International Journal of Business Intelligence and Data Mining, vol. 14, pp. 106-120, 2019.

[6] Sekath Varma, K. Nithiyananthan, "MATLAB Simulations based Identification Model for Various Points in Global Positioning System," International Journal of Computer Applications, vol. 138, no. 13, pp15-18, 2016.

[7] S. Samson Raja, R. Sundar, A.A mudha, K. Nithiyananthan, "Unit Commitment Calculator Model for Three phase Power System Network," International Journal of Power and Renewable Energy Systems, vol 3, no. 1, pp. 37-42, 2016.

[8] K. Gowrishankar, K. Nithiyananthan, Mani Priyanka, Venkatesan, G., "Neural network based mathematical model for feed management technique in aquaculture," Journal of Advanced Research in Dynamical and Control Systems, vol. 18, no.1, pp. 1142-1161, 2017.

[9] Sing, Tan Yong and Bin Siraj, Syahrel Emran and Raguraman, Raman and Marimuthu, Pratap Nair and Nithiyananthan, K., "Cosine similarity cluster analysis model based effective power systems fault identification," International Journal of Advanced and Applied Sciences, vol 4, no1, pp. 123-129, 2017.

[10] Pratap Nair., Nithiyananthan, K., Dhinakar, P., "Design and development of variable frequency ultrasonic pest repeller," Journal of Advanced Research in Dynamical and Control Systems, vol. 9, no. 12, pp. 22-34, 2017.

[11] K.Nithiyananthan, Sundar, R., Ranganathan, T., Samson Raja, S., "Virtual instrumentation based simple economic load dispatch estimator model for 3-phase power system network," Journal of Advanced Research in Dynamical and Control Systems, vol. 9, no. 11, pp. 9-15, 2017.

[12] K.Nithiyananthan, T.Samson Raja, Sundar, R., Amudha, A., "Virtual stability estimator model for three phase power system network," Indonesian Journal of Electrical Engineering and Computer Science, vol. 4, no. 3, pp. 520-525, 2016.

[13] Pratap Nair, M., K.Nithiyananthan, "An effective cable sizing procedure model for industries and commercial buildings," International Journal of Electrical and Computer Engineering, vol. 6, no. 1, pp. 34-39, 2016.

[14] Pratap Nair, M., K.Nithiyananthan, "Feasibility analysis model for mini hydropower plant in Tioman Island, Malaysia," Distributed Generation and Alternative Energy Journal, vol. 31, no. 2, pp. 36-54, 2016.

[15] K.Nithiyananthan, Umasankar, "Environment friendly voltage up-gradation model for distribution power systems," International Journal of Electrical and Computer Engineering, vol. 6, no. 6, pp. 2516-2525., 2016.

[16] Sureshkumaar, G., Kannan, N., Thomas, S., Karthikeyan, S.P., "Matlab/simulink simulations based modified sepic DC to DC converter for renewable energy applications," Journal of Advanced Research in Dynamical and Control Systems, vol. 11, no. 4, pp. 285-295, 2019.

[17] G. Venkatesan, K. Nithiyananthan, "Static and Transient Thermal Analysis of Power Factor Converters in Switched Reluctance Motor Drive," Journal of Advanced Research in Dynamical \& Control Systems, vol 10, no 13, pp.1656-1662, 2018.

[18] K.Nithiyananthan, Ramachandran, V., "Effective data compression model for on-line power system," International Journal for Engineering Modelling, vol. 27, no. 3-4, pp. 101-109, 2014.

[19] K.Nithiyananthan, Ramachandran, V., "Distributed mobile agent model for multi area power systems automated online state estimation," International Journal of Computer Aided Engineering and Technology, vol. 5, no. 4, pp. 300-310, 2013.

[20] K.Nithiyananthan, Ramachandran, V., "Versioning-based service-oriented model for multi-area power system online economic load dispatch," Computers and Electrical Engineering, vol. 39, no. 2, pp. 433-440, 2013.

[21] K.Nithiyananthan, Ramachandran, V., "Location independent distributed model for on-line load flow monitoring for multi-area power systems," International Journal for Engineering Modelling, vol. 24, no. 1-4, pp. 21-27, 2011.

[22] K.Nithiyananthan, Loomba, A.K., "MATLAB/Simulink based speed control model for converter controlled DC drives, International Journal for Engineering Modelling, no. 24 no. 1-4, pp. 49-56, 2011.

[23] Thomas, S., K. Nithiyananthan., Eski, A., "Investigations on transient behavior of an energy conservation chopper fed DC series motor subjected to a change in duty cycle," Journal of Green Engineering, vol. 9, no. 1, pp. 92-111. 2019.

[24] K.Nithiyananthan, Ramachandran, V., "A plug and play model for JINI based on-line relay control for power system protection," International Journal for Engineering Modelling, vol. 21, no. 1-4, pp. 65-68, 2008.

[25] K.Nithiyananthan, Ramachandran, V., "A distributed model for capacitance requirements for self-excited induction generators," International Journal of Automation and Control, vol. 2, no. 4, pp. 519-525, 2008. 
[26] Nithiyananthan. K, Ramachandran.V, "Component Model Simulations for Multi-Area Power System Model for On-Line Economic Load Dispatch," International Journal for Emerging Electric Power Systems, vol 1, no $2,2004$.

[27] K. Nithiyananthan., Elavenil. V., "CYMGRD Based Effective Earthling Design Model for Substation," International Journal for Computer Applications in Engineering Sciences Asia, vol. 1, no 3, pp. 341-346, 2011.

[28] K.Nithiyananthan, Ramachandran, V., "Distributed mobile agent model for multi-area power system on-line economic load dispatch," International Journal for Engineering Modelling, vol. 17, no. 3-4, pp. 87-90, 2004.

[29] Youssef A. Mobarak, A.M. Hemeida, Nithiyananthan Kannan, Voltage and Frequency based Load Dependent Analysis Model for Egyptian Power System Network, Journal of Advanced Research in Dynamical \& Control Systems, USA. Vol 11, No 6, 2019 Pp.971-978.

[30] Low Kak Hau, Gowrishankar, Nithiyananthan. K, "Development Of Prototype Model For Wireless Based Control Pick And Place Robotic Vehicle," TELKOMNIKA Indonesian Journal of Electrical Engineering, vol. 14, no. 1, pp 110-115, April 2015.

[31] K.Nithiyananthan, Ramachandran, V., "A distributed model for multi-area power systems on-line dynamic security analysis," IEEE Region 10 Annual International Conference, Proceedings/TENCON, vol. 3, pp. 1765-1767, 2002.

[32] K.Nithiyananthan, Ramachandran, V., "EJB based component model for distributed load flow monitoring of multiarea power systems," International Journal for Engineering Modelling, vol. 15, no. 1-4, pp. 63-67, 2002.

[33] Sureshkumaar, G., K.Nithiyananthan., Thomas, S, "MATLAB/SIMULINK based simulations of KY converter for PV panels powered led lighting system," International Journal of Power Electronics and Drive Systems, vol. 10, no. 4, pp. 1885-1893, 2019.

[34] VimalRaj, S., Suresh Kumar, G., Thomas, S., K.Nithiyananthan, "MATLAB/SIMULINK based simulations on state of charge on battery for electrical vehicles," Journal of Green Engineering, vol. 9, no. 2, pp. 255-269, 2019.

[35] Mobarak, Y.A., K.Nithiyananthan, "Vertically integrated utility power system structures for egyptian scenario and electricity act," Journal of Advanced Research in Dynamical and Control Systems, vol. 11, no. 7, pp. 766-772. 2019.

[36] A. Camargo, et al., "An image processing based algorithm to automatically identify plant disease visual symptoms," Biosystems Engineering, vol. 102, no. 1, pp. 9-21, 2009.

[37] D. Sabine Bauer, et al., "The Potential of Automatic Methods of classification to identify Leaf diseases from Multispectral images", Precision Agric, vol 12, pp.361-377, 2011.

[38] D. Al-Bashish, et al., "Detection and classification of leaf diseases using K-means-based segmentation and neural networks based classification," Inform. Technol. J., vol. 10, pp. 267-275, 2011.

[39] A. Clément, et al., "A New Colour Vision System to Quantify Automatically Foliar Discolouration Caused by Insect Pests Feeding on Leaf Cells," Biosystems Engineering, vol. 133, pp. 128-140, 2015. ISSN 1537-5110, doi: 10.1016/j.biosystemseng.2015.03.007

[40] R. Zhou, et al., "Disease Detection of Cercospora Leaf Spot in Sugar Beet by Robust Template Matching", Computers and Electronics in Agriculture, vol. 108, pp. 58-70, 2014.

[41] J.G.A Barbedo, et al., "A New Automatic Method for Disease Symptom Segmentation in Digital Photographs of Plant Leaves,” European Journal of Plant Pathology, vol. 147, no. 2, pp. 349-364, 2016.

[42] D. P Hughes, et al.,"An Open Access Repository of Images on Plant Health to Enable the Development of Mobile Disease Diagnostics," Cornell Universty 2015.

[43] A. Borji, et al., "Salient Object Detection: A Benchmark," IEEE Trans. Image Process., vol. 24, no. 12, pp. 5706-5722, Dec. 2015.

[44] Bardsley, et al., "Reliability and accuracy of visual methods to quantify severity of foliar bacterial spot symptom on peach and nectarine," Plant Pathology, vol. 62, no. 2, 2012.

[45] Zhang, et al., "Orthogonal Locally Discriminant Projection for Classification of Plant Leaf Diseases", Ninth International Conference on Computational Intelligence and Security, pp. 241- 245, 2013.

[46] Pilli, et al., "eAGROBOT-A robot for early crop disease detection using image processing," International Conference on Electronics and Communication Systems (ICECS), pp. 1-6, 2014.

[47] Nithiyananthan.K, Mobarak, Y., Alharbi, F.Application of cloud computing for economic load dispatch and unit commitment computations of the power system network,Advances in Intelligent Systems and Computing, 1108 AISC,2020 pp. 1179-1189. 